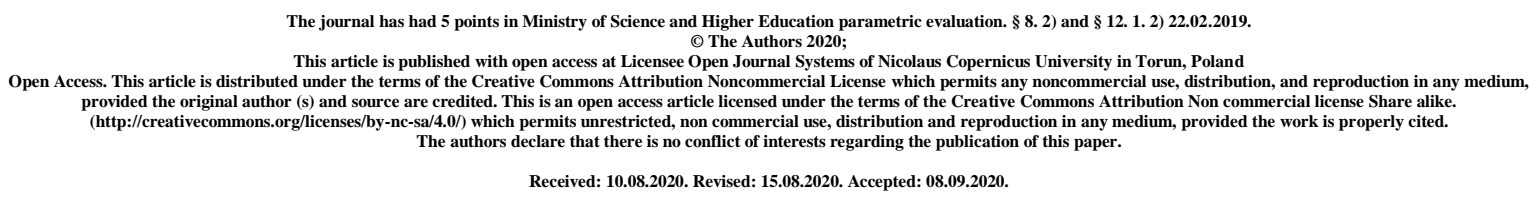

\title{
Impact of coffee on human health
}

\section{Szuster Ewa, Pawlikowska Anna, Mandera Amanda, Kostrzewska Paulina}

\begin{abstract}
Poland
Abstract

Coffee is considered as one of the most popular beverages in the world. There are many different methods of preparation which can change the taste but also it could limit the level of dipertenes which raise blood cholesterol. For many years it was thought that the impact of coffee on human health is not very positive. Surprisingly coffee consumption is associated with lower risk of the type 2 diabetes mellitus and lower cancer risk. It also decreases mortality from cardiovascular disease, coronary heart disease, and stroke. Summarizing, the results of the analyzed studies show positive impact of coffee on human health. To maintain the advantages of this beverage, amount of caffeine, intake of sugar or cream should be limited.
\end{abstract}

Key words: coffee; caffeine; cardiovascular diabetes 


\section{Introduction}

Coffee is one of the most popular beverages all over the world - over $80 \%$ of adult Poles declare drinking coffee regularly, most of them $(60 \%)$ drink coffee at least one a day and $16 \%$ drink a few cups of coffee every day. The average annual coffee consumption per capita in Poland is about $2.8 \mathrm{~kg}$. 7 tons of coffee are drunk every year around the world. [1,2] There are many types of coffee which depends on the degree of roasting, type of beans and method of preparation. Coffee is one of the main sources of caffeine to the diet. [3] Caffeine content varied widely, ranging from 40 to $180 \mathrm{mg}$ per cup of coffee depending on type of beans, roasting methods etc. [4] Impact of coffee and caffeine on human's health has been discussed by many researchers.

\section{Methods of preparation}

Coffee contains a whole lot of different substances, one of the most important being caffeine. In recent years, attention has been paid to the methods of preparing coffee, which vary slightly from country to country. Moreover, it has been proven that the method of preparing coffee has an influence on the lipid fraction. The lipid content and composition of boiled, filtered, dripped, Turkish and espresso coffees prepared from roasted beans of Coffea arabica and Coffea robusta. While coffee brews filtered through filter paper contained less than $7 \mathrm{mg}$ lipids, those prepared by boiling without filtering and espresso coffee reached 60-160 $\mathrm{mg}$ lipids/150-ml cup. Coffee brew filtered through a metal screener contained $50 \mathrm{mg}$ lipids/150ml cup. [5]

On this basis, attempts are made to develop the most favorable recommendations for coffee consumption, which should take into account the method of its preparation, the amount consumed as well as predisposing risk factors, such as hypertension, hyperlipidemia. [6]

The semi-automatic espresso machine, also known as a manual, semi-automatic or lever coffee machine, is the most popular coffee machine.

Due to the very short contact between the water and the ground coffee beans, it must be ground properly. If the beans are ground too coarsely, the water will flow through them too quickly, the brewing process will not take place properly and the coffee will be too weak.

For one cup of espresso, about 7 grams of ground coffee are needed, although you can make a single serving with 16 grams of ground coffee. [7]

French press (press pot, coffee press, cafetiere or cafetiere a piston), as the name suggests, was invented in France, but it gained the greatest popularity in Denmark and Great Britain. It was first patented in 1929 by the Italian designer Attilio Caliman.

It is a glass or metal cylinder with a piston inside, at the end of which there is a strainer, corresponding to the width of the vessel. This is one of the fastest and easiest ways to make coffee. The main advantage of this type of device is the ability to separate the coffee grounds from the infusion by means of a piston with a sieve.

When brewing coffee in French press, as with other brewing methods, the proportions are important. About 6 grams of coffee should be used for about $100 \mathrm{ml}$ of water. 
AeroPress is an easy-to-use device - it resembles a large syringe. It was invented in 2005 by Alan Adler, so it is the youngest device for drip coffee brewing. It combines the advantages of French press and drip. The entire coffee brewing process takes only a few minutes. The device consists of a piston, a sieve with a filter and a cylinder through which the finished coffee brew is pressed. AeroPress extracts maximum juiciness and natural fruity notes from coffee, it also emphasizes its acidity. Aeropress also allows the coffee to be brewed using the reverse method, thanks to which different taste qualities of coffee are obtained using the same beans. [8]

The coffee maker was created as an alternative to the espresso machine, it was invented in the 1930s by Antonio Bialetti in Italy. The brewing process should be a slow, gentle stream. [9]

Drip is the most classic method of preparing coffee. For this purpose, we use a special device that heats the water by itself and floods the coffee with it - a filter coffee maker or a glass or porcelain vessel, which we place directly on the cup - drip, chemex. The infusion is delicate, with a more tea-like consistency, and rich in fruity aromas and caffeine. Chemex gives a clear, even tea infusion with a velvety texture and a delicate body. [10]

The siphon was invented in the 1830s. This is one of the oldest methods of brewing coffee.

Turkish coffee dates back to the 16th century and is probably the oldest coffee made today. In 2013, the tradition of brewing and drinking coffee in Turkey was entered on the UNESCO intangible heritage list. [11]

Cold brew is coffee prepared without the use of hot water. Due to the lower acidity level of cold brew coffee, it is also sweeter in taste. Cold brews also contain more caffeine than traditional coffee because the maceration process coffee beans are in contact with water longer. [8]

\section{Caffeine}

Caffeine (1,3,7-trimethylxanthine) is the most commonly consumed stimulant worldwide. [12] The main natural sources of caffeine in diet are coffee beans, tea leaves, guarana, cocoa beans and kola nuts. [13] Caffeine is also an ingredient in energy drinks, chocolate and in medications. Because of its wide consumption and presence many scientists have investigated the effect of caffeine on human health. [14] Consequently regulatory agencies worldwide have evaluated caffeine safety and have issued guidance regarding daily intake amounts. [15] In 2003 Nawrot et al. proved that for the healthy adult population daily caffeine intake at dose level up to $400 \mathrm{mg} /$ day, for pregnant women $300 \mathrm{mg} /$ day and $2.5 \mathrm{mg} / \mathrm{kg} / \mathrm{day}$ has not adverse effects in five main outcomes such as 1.general toxicity,2. cardiovascular, 3.bone and calcium, 4.behavior, 5. development and reproductive toxicity. The potential lethal dose of caffeine is about $10 \mathrm{~g}$. [14]

Wikoff et al. perform systematic review of the potential adverse effects of caffeine consumption taking into consideration 740 full-text review. The study confirmed Nawrot's caffeine acceptable doses. 
However intake below $400 \mathrm{mg} /$ day may affect some sensitive individuals who are prone to anxiety or sleep disruption. [16] Also Schubert et al. examined literature that assessed the effects of caffeine and coffee on energy intake, gastric emptying, appetite- related hormones and perceptual measures of appetite. The study showed that coffee administered 3-4.5h before a meal affects food and macronutrient intake minimally, but caffeine administered 0.5-4h before a meal may suppress acute energy intake. [17]

\section{Cardiovascular disease}

The effect of caffeine on the cardiovascular system has been studied in numerous research papers, which shows that coffee consumption was associated with a lower risk of mortality from cardiovascular disease, coronary heart disease, and stroke in a non-linear relation. It was estimated that the largest reduction in relative risk was at three cups a day. There was no apparent variation of this association by sex. There was no significant association between consumption and risk of venous thromboembolism. [18]

In the population U.S. adults were investigated the relationship between caffeine and direct and indirect caffeine metabolites with hypertension. It was concluded that final metabolites of caffeine (namely 3-MU, 7-MU, 3-MX and 7-MX), but not caffeine, significantly reduce the chances of hypertension in this population. [19]

Coffee consumption seems to be associated with decreased mortality in general and caffeinated-beverages seem to be related with lower risk of high blood pressure in nonsmokers. Despite the widespread consumption of coffee and caffeine in food and beverages there is no specific recommendation regarding coffee or caffeine intake in current hypertension guidelines. It is thought that there is currently no evidence that people with high blood pressure should refrain from caffeine when taken in reasonable amounts. [20]

Caffeine effects on cholesterol were investigated in trials, with exposures ranging from 180 to $475 \mathrm{mg}$ caffeine/day. Research results showed a lack of effect of caffeinated-beverages on cholesterol at intakes below and above the comparator.

Summarizing the results in the cardiovascular effects category, there was no consistent effect of caffeine on heart-rate variability at intakes below $40 \mathrm{mg}$ or above $500 \mathrm{mg}$, which confirms that $400 \mathrm{mg}$ caffeine/day in healthy adults is an acceptable intake and is not associated with significant change in heart-rate variability. [21]

\section{Diabetes mellitus}

Coffee consumption is also associated with lower risk of the type 2 diabetes mellitus. It is caused by anti-inflammatory, antioxidative and thermogenic effects. The obtained results suggest that caffeinated and decaffeinated coffee have similar impact on diabetes mellitus. Filtered coffee such as Drip brewed contains the lowest amount of dipertenes which raise blood cholesterol and triglyceride levels in contrast to unfiltered coffee like Turkish or French press. Coffee consumption was also associated with higher levels of adiponectin and lower leptin levels in serum. It also caused reduced markers for inflammation and metabolic dysfunction. [22] 


\section{Is coffee a carcinogen?}

Coffee contains acrylamide which is considered as "probably carcinogen". It is produced by roasting coffee beans in high temperature. Many animals studies have shown that acrylamide is a carcinogen. [23] Nevertheless studies used doses about 1000-10000 times higher than normal consumption in food so there is no evidence that coffee is a definitely carcinogen. [24] Tian et al have shown the association between drinking coffee and lower risk of colorectal and colon cancer. [25] Coffee intake can also reduce liver and prostate cancer risk. On the other hand, there is an association between high coffee intake, especially among non-smoking men and the higher risk of the bladder cancer. The effect on breast cancer depends on caffeine metabolism. CYP1A2 is involved in metabolism of caffeine but it also an estrogen metabolism. Estrogens have a significant role in ER+ breast cancer pathogenesis. CYP1A2*F genotype and coffee consumption may slow the risk of the breast cancer. [24]

\section{Conclusion}

Results of the analyzed studies show positive impact of coffee on human health. Coffee consumption is associated with lower risk of the type 2 diabetes mellitus and lower cancer risk. It also decreases mortality from cardiovascular disease, coronary heart disease, and stroke. It is also important to take under consideration the proper type of brewing or limit the use of milk, cream and sugar. 


\section{References}

1. The Current State of the Global Coffee Trade, http://www.ico.org/monthly_coffee_trade_stats.asp

2. Rynek kawy w Polsce, https://analizarynku.eu/rynek-kawy-w-polsce

3. Mitchell, D. C., Hockenberry, J., Teplansky, R., \& Hartman, T. J. (2015). Assessing dietary exposure to caffeine from beverages in the U.S. population using brand-specific versus category-specific caffeine values. Food and Chemical Toxicology, 80, 247252. https://doi.org/10.1016/j.fct.2015.03.024

4. Abdelfattah R, Kamran H, Lazar J, Kassotis J. Does Caffeine Consumption Increase the Risk of New-Onset Atrial Fibrillation?. Cardiology. 2018;140(2):106-114. doi:10.1159/000489843

5. Ratnayake WM, Hollywood R, O'Grady E, Stavric B. Lipid content and composition of coffee brews prepared by different methods. Food Chem Toxicol. 1993;31(4):263-269. doi:10.1016/0278-6915(93)90076-b

6. Pirich C, O'Grady J, Sinzinger H. Coffee, lipoproteins and cardiovascular disease. Wiener Klinische Wochenschrift. 1993 ;105(1):3-6.

7. Arii Y, Nishizawa K. Espresso coffee foam delays cooling of the liquid phase. Biosci Biotechnol Biochem. 2017;81(4):779-782. doi:10.1080/09168451.2017.1280662

8. Angeloni G, Guerrini L, Masella P, et al. What kind of coffee do you drink? An investigation on effects of eight different extraction methods. Food Res Int. 2019;116:13271335. doi:10.1016/j.foodres.2018.10.022

9. Khan MA, Ahamad T, Saquib M, Hussain MK, Khan MF. Unmodified household coffee maker assisted extraction and purification of anticancer agents from Dillenia indica fruits [published online ahead of print, 2019 May 28]. Nat Prod Res. 2019;1-4. doi:10.1080/14786419.2019.1608546

10. Gloess, A.N., Schönbächler, B., Klopprogge, B., D’Ambrosio, L., Chatelain, K., Bongartz, A., Strittmatter, A., Rast, M., \& Yeretzian, C. (2013). Comparison of nine common coffee extraction methods: instrumental and sensory analysis. European Food Research and Technology, 236, 607-627.

11. Derossi A, Ricci I, Caporizzi R, Fiore A, Severini C. How grinding level and brewing method (Espresso, American, Turkish) could affect the antioxidant activity and bioactive compounds in a coffee cup. J Sci Food Agric. 2018;98(8):3198-3207. doi:10.1002/jsfa.8826

12. B.B. Fredholm, K. Battig, J. Holmen, A. Nehlig, E.E. Zvartau Actions of caffeine in the brain with special reference to factors that contribute to its widespread use Pharmacol. Rev., 51 (1999), pp. 83-133

13. J.J. Barone, H.R. Roberts, Caffeine consumption, Food and Chemical Toxicology, Volume 34, Issue 1, 1996, Pages 119-129

14. P. Nawrot, S. Jordan, J. Eastwood, J. Rotstein, A. Hugenholtz \& M. Feeley (2003) Effects of caffeine on human health, Food Additives \& Contaminants, 20:1, 130, DOI: $10.1080 / 0265203021000007840$

15. Barbara E Millen, Steve Abrams, Lucile Adams-Campbell, Cheryl AM Anderson, J Thomas Brenna, Wayne W Campbell, Steven Clinton, Frank Hu, Miriam Nelson, Marian L Neuhouser, Rafael Perez-Escamilla, Anna Maria Siega-Riz, Mary Story, Alice H Lichtenstein, The 2015 Dietary Guidelines Advisory Committee Scientific Report: 
Development and Major Conclusions, Advances in Nutrition, Volume 7, Issue 3, May 2016, Pages 438-444, https://doi.org/10.3945/an.116.012120

16. D. Wikoff, B T. Welsh, Rayetta Henderson, Gregory P. Brorby, Janice Britt, Esther Myers, Jeffrey Goldberger, Harris R. Lieberman, Charles O'Brien, Jennifer Peck, Milton Tenenbein, Connie Weaver, Seneca Harvey, Jonathan Urban, Candace Doepker, Systematic review of the potential adverse effects of caffeine consumption in healthy adults, pregnant women, adolescents, and children, Food and Chemical Toxicology, Volume 109, Part 1, 2017, Pages 585-648,

17. Schubert MM, Irwin C, Seay RF, Clarke HE, Allegro D, Desbrow B. Caffeine, coffee, and appetite control: a review. Int J Food Sci Nutr. 2017;68(8):901-912. doi:10.1080/09637486.2017.1320537

18. Poole R, Kennedy OJ, Roderick P, Fallowfield JA, Hayes PC, Parkes J. Coffee consumption and health: umbrella review of meta-analyses of multiple health outcomes [published correction appears in BMJ. 2018 Jan 12;360:k194]. BMJ. 2017;359:j5024. Published 2017 Nov 22. doi:10.1136/bmj.j5024

19. Ngueta G. Caffeine and caffeine metabolites in relation to hypertension in U.S. adults. Eur J Clin Nutr. 2020;74(1):77-86. doi:10.1038/s41430-019-0430-0

20. Guessous I, Eap CB, Bochud M. Blood pressure in relation to coffee and caffeine consumption. Curr Hypertens Rep. 2014;16(9):468. doi:10.1007/s11906-014-0468-2

21. Doepker C, Franke K, Myers E, et al. Key Findings and Implications of a Recent Systematic Review of the Potential Adverse Effects of Caffeine Consumption in Healthy Adults, Pregnant Women, Adolescents, and Children. Nutrients. 2018;10(10):1536. Published 2018 Oct 18. doi:10.3390/nu10101536

22. Mattias Carlström, Susanna C Larsson, Coffee consumption and reduced risk of developing type 2 diabetes: a systematic review with meta-analysis, Nutrition Reviews, Volume 76, Issue 6, June 2018, Pages 395-417, https://doi.org/10.1093/nutrit/nuy014

23. Wierzejska R. Coffee consumption vs. cancer risk - a review of scientific data. Rocz Panstw Zakl Hig. 2015;66(4):293-298.

24. DiNicolantonio JJ, O'Keefe JH. Coffee Is Not a Carcinogen. Mo Med. 2018;115(3):197-198.

25. Tian C, Wang W, Hong Z, Zhang X. Coffee consumption and risk of colorectal cancer: a dose-response analysis of observational studies. Cancer Causes Control. 2013;24(6):1265-1268. doi:10.1007/s10552-013-0200-6 